\title{
The Emerging Role of Vitamin D3 in Women's Health
}

\author{
Khadilkar Suvarna Satish
}

Published online: 21 June 2013

(C) Federation of Obstetric \& Gynecological Societies of India 2013

Vitamin D3, often called the "sunshine Vitamin," is a very important nutrient for women's health. Despite its discovery 100 years ago, Vit D has emerged as one of the most controversial nutrients and prohormones of the $21 \mathrm{st}$ century, and a lot of research has been in place on this molecule. The research leads us to newer therapies with newer concepts. Research has now shown Vit D's indisputable role in both inherent and adaptive immunity. This editorial will take an account of the current view on the impact of vitamin D deficiency on women's health.

We already know that Vit D is a Steroid prohormone ("conditional" Vitamin); it is synthesized in skin under ultra-violet light exposure. 7-Dehydrocholesterol present in the skin absorbs UV light over wavelengths of 290-300 nm [UVB ] to synthesize Vit D3. Synthesis in the skin epidermis takes place over several days; the quantity (intensity) and quality (appropriate wavelength) of sunlight are both important This biosynthesis can be inadequate due to poor dietary intake, absorption, or poor exposure to sunlight [UVB]. The deficiency can occur because of fat malabsorption, anticonvulsant use, chronic kidney disease, and obesity and is seen in high-risk groups like elderly

Khadilkar S. S., Professor and HOD

Department of Obstetrics and Gynaecology, RCSMGMC,

Kolhapur, India

Khadilkar S. S. ( $\square)$, Professor and HOD

61/62 New Clement Court, Off Gokhale Road [North], Opposite Amar Hind Mandal, Shivaji park, Dadar, Mumbai 400028, India e-mail: suvarnakhadilkar@yahoo.com women, dark-skinned people, people from areas with a thick layer of ozone, women using sunscreen lotions, and people from urban areas.

In urban and polluted areas, the UV light of 290-300$\mathrm{nm}$ wave length gets filtered out; hence, skin may not get enough of this light. Therefore, there is a high rate of Vit D deficiency even among the urban population. Hence, foods and dietary supplements are necessary. There are two major forms of dietary Vit D: Cholecalciferol (Vit D3) and Ergocalciferol (Vit D2). Cod liver oil, salmon and sardines, fortified milk, egg, fortified yogurt, mushrooms, fortified soy products, oysters, and fortified cereals are rich sources of Vit D. Under situations of minimal exposure to sunlight, a specific recommendation of a daily supplement of $400 \mathrm{IU}$ $(10 \mu \mathrm{g})$ is retained for the Indian population. RDA for pregnant women is $200 \mathrm{IU}$ per day and the maximum safe daily dose is 2,000 IU. Due to widespread deficiency, testing for vitamin D levels is important for most individuals. A serum concentration of 25 -hydroxyvitamin $\mathrm{D}$ is the best indicator of vitamin D status as it is the major circulating form of the vitamin in the body.

\section{Traditional Role}

Traditionally, Vit D3, Cholecalceferol, and Calcitriol $(1,25(\mathrm{OH}) 2 \mathrm{D} 3)$ had a role in only calcium metabolism and bone mineral metabolism. It works with the parathyroid hormone (PTH), acts on the kidneys, bone, and intestine, and influences gene expression. It regulates its own synthesis by 
decreasing synthesis of mRNA for 1-alpha hydroxylase. It influences bone mineral metabolism and calcium/phosphorus homeostasis by increasing synthesis of mRNA for calbindin-D, alkaline phosphatase, and other proteins. It maintains calcium and phosphorus homeostasis.

For decades, it was thought that only the kidney has the capacity to metabolize $25(\mathrm{OH}) \mathrm{D}$; however, now extrarenal metabolism has been demonstrated in every organ system in the body [1]. VDR and MARR receptors for Vit D are present in all tissues. During pregnancy, the placenta is probably the most prominent site for extrarenal activation of Vit D [2]. It appears that the extrarenal function of Vit D has more to do with immune function than with calcium metabolism and homeostasis. The observations of Mellanby and others supported this fact [3].

\section{The Emerging Roles of Vit D}

It is now considered important in cell differentiation, proliferation, and immune function. It is an important factor in prevention/treatment of some forms of cancer, osteoporosis, rheumatoid arthritis, multiple sclerosis, hypertension, cardiovascular disease, obesity, psoriasis, and psychiatric diseases. The role of vitamin D in pregnancy is also taking new dimensions.

\section{Vit D and Pregnancy}

Beyond childhood, severe Vit D deficiency can occur in young women, including those who are pregnant, with higher risk with advancing age in a woman's lifecycle. There can be some calcium loss during pregnancy through fetal demands and increased urinary calcium excretion, which increases with advancing pregnancy. Throughout gestation, if a woman is Vit D deficient, it appears to impact fetal bone health more than maternal health [4-6]. There are different deficiency levels. The risk of rickets increases significantly when the total circulating $25(\mathrm{OH}) \mathrm{D}$ falls below $10 \mathrm{ng} / \mathrm{mL}$ ( $25 \mathrm{nmol} / \mathrm{L})$, whereas cathelicidin mRNA expression as a marker of immune function continues to be suppressed until $25(\mathrm{OH}) \mathrm{D}$ circulating levels reach at least $20 \mathrm{ng} / \mathrm{mL}(50 \mathrm{nmol} / \mathrm{L})$ [7]. The recently revised Institute of Medicine's (IOM) 2010 criterion for Vit $\mathrm{D}$ deficiency of total circulating $25(\mathrm{OH}) \mathrm{D}$ is $<20 \mathrm{ng} / \mathrm{mL}$ (50 nmol/L), Optimal serum concentrations of $25(\mathrm{OH}) \mathrm{D} 3$ are at or above $30 \mathrm{ng} / \mathrm{mL}(\geq 75 \mathrm{nmol} / \mathrm{L})$, and Vit D toxicity is present when levels are at or above $150 \mathrm{ng} / \mathrm{mL}$ (374 nmol/L) [8].

Rates of deficiency of Vit D are more with women who have darker pigmentation and women who have limited access to sunlight, through limited outdoor activity, type of clothing, cultural practices, or thorough use of sunscreen when outdoors [9]. Vit D deficiency exists in a higher percentage in obese women. Women including pregnant women, with a BMI $>30$, are at increased risk of Vit D deficiency [9]. The adipose tissue serves as a repository for Vit D that does not get into the circulation. The problem may be further compounded by limited sunlight exposure and calorically rich but nutrient-poor diets such that multiple nutrients may be deficient, affecting both the mother and her developing fetus.

Current guidelines for daily Vit D intake during pregnancy range from 200 international units (IU) per day to 400 IU. We have always worried that too much Vit D during pregnancy could cause birth defects, and under current guidelines anything over 2,000 IU per day is still considered potentially unsafe for anyone, not just the pregnant women. As per recent research, higher dosages of Vit D are not just safe during pregnancy, but doubling it may actually reduce the risk of complications.

In a study, 500 women who were at least 12 weeks pregnant took 400, 2000, or 4000 IU of Vit D per day. The women who took 4,000 IU were less prone to onset of preterm labor, giving birth prematurely, or developing infections. Vit D intoxication is extremely rare and easy to treat. Pregnant women who get too little Vit D are more likely to develop life-threatening high blood pressure (preeclampsia) and are also more likely to require a Cesarean section. They concluded that giving 4,000 IU a day to pregnant women may not only improve birth outcomes but also does not cause toxicity [10].

Pregnant women with a serum level of $25-\mathrm{OH}$ Vit D $<75 \mathrm{nmol} / \mathrm{L}$ are considered to be Vit D3 deficient [11].

Until recently, it was thought that Vit D deficiency was common only in high-risk women (women with dark skin and those with minimal exposed skin), but it is quite high even in low-risk women.

All women therefore should be offered testing for Vit D status in early pregnancy and recommended supplementation if deficient [12]. Women with a 25-OH Vit D3 $<75 \mathrm{nmol} / \mathrm{L}$ are considered Vit $\mathrm{D}$ deficient and should have a dietary assessment for calcium intake. They should receive a higher dose up to 1000 IU. They should be offered retesting at 28 weeks of pregnancy. If the high dose of Vit D does not improve the serum Vit D levels, then malabsorption syndrome (such as celiac disease) should be ruled out or else the patient may be non-compliant.

Pregnant women should have enough Vit D at the time of delivery to insure sufficient Vit D levels in their baby for the first 4-6 months of life.

The transplacental passage of maternal 25-OH Vit D3 is the sole source of Vit D in the developing fetus. Therefore, infants are wholly dependent on their mother for their Vit D status. Infants born to Vit D-deficient mothers will be Vit 
$\mathrm{D}$ deficient and hence will require supplementation in the form of cholecalciferol bolus (50,000 IU) dose orally. The obstetricians must understand the importance of vitamin $\mathrm{D}$ supplementation to pregnant and nursing mothers, which will go a long way in preventing rickets.

\section{Emerging Role of Vitamin D in Other Diseases}

The role of Vit D in osteoporosis and muscle weakness is undisputable. But, there is a recent trend to give a higher dose of Vit D to prevent the osteoporotic fracture.

Trials using $700-800 \mathrm{IU} / \mathrm{d}$ oral vitamin $\mathrm{D}$ with or without calcium supplementation found a significant $23-43 \%$ reduction in risk of a hip fracture and any nonvertebral fracture versus calcium or placebo [13-15]. A Dutch study with vitamin D 400 IU over 3.5 years showed no effect on the risk of hip fracture [16]. Therefore, whether or not $400 \mathrm{IU}$ vitamin D is enough to prevent fracture in healthy elderly subjects with normal BMD needs further research.

It has been reported that increased vitamin D levels can improve muscle performance and thus reduce the incidence of falls. In a 5-month randomized controlled trial, elderly people in a nursing home receiving $800 \mathrm{IU}$ of vitamin D2 plus calcium daily exhibited a $72 \%$ reduction in the risk of falls as compared with the placebo group [17]. Thus, vitamin $\mathrm{D}$ does reduce muscle weakness.

Reduced blood pressure has been found in people taking oral supplementation of vitamin D. Skin exposure to UVB, which is the major source of vitamin $\mathrm{D}$ formation, has been linked with lower blood pressure [18-20]. An 8-week single-intervention study of 148 vitamin D-deficient elderly women demonstrated a $9 \%$ decrease in systolic blood pressure with supplemental vitamin D (800 IU) plus calcium (1200 mg) compared with calcium alone [21].

Multiple sclerosis is an autoimmune disease which is more prevalent in temperate climates than the tropics and is also seen much more commonly in women. It is associated with lower serum vitamin D levels, and Vit D supplementation may have a preventive role in multiple sclerosis.

The first study indicating that sunlight exposure may lower the risk of cancer was made almost seven decades ago [22].

Vitamin D is one of the most potent hormones for regulating cell growth. It was discovered that many cell types contain vitamin $\mathrm{D}$ receptors. The protective relationship between sufficient vitamin $\mathrm{D}$ status and a lower risk of cancer has been found in many studies. It has been reported that breast and colorectal cancer can be reduced by $50 \%$ with the concentration of 25-hydroxyvitamin D being $>32 \mathrm{ng} / \mathrm{mL}[23,24]$. The higher the Vit D level, the lower the risk of cancer. A 4-year trial on postmenopausal women showed that $1100 \mathrm{IU} /$ day vitamin D plus $1,400-1,500 \mathrm{mg} /$ day calcium can substantially reduce risk of all cancers [23].

Vitamin D acts as an immunosuppressant in rheumatoid arthritis as well.

It has an effect on both type I and type II diabetes mellitus. A study of 83,779 women with no history of diabetes over 2-4 years showed that a combined daily intake of $>1,200 \mathrm{mg}$ calcium and $>800 \mathrm{IU}$ vitamin $\mathrm{D}$ was associated with a $33 \%$ lower risk of type 2 diabetes as compared with a daily intake of $<600 \mathrm{mg}$ of calcium and $<400$ IU of vitamin D [25]. Another study on 10,366 children in Finland over 31 years indicated that $2000 \mathrm{IU}$ of vitamin $\mathrm{D}$ per day during their first year of life can reduce the risk of type 1 diabetes by $\sim 80 \%$ [26].

Tuberculosis is associated with lower Vit D levels. Before the antikoch's treatment was available, high dosages of Vit $\mathrm{D}$ were given to patients. We see this disease in urban areas in women with a specific dressing style which prevents adequate sunlight exposure.

To summarize, Vit D deficiency is highly prevalent and contributes to women's health greatly. Getting too little vitamin $\mathrm{D}$ is worse than getting too much. Although we have been taught that vitamin D is toxic in large amounts, Vitamin D intoxication is extremely rare and easy to treat. Newer reports are changing our ideas about the optimal Vit D status and the role of Vit D in health, especially in relation to modern chronic diseases affecting women. It must be remembered that some populations are still very much undertreated, and pregnancy-associated complications can be reduced with correction of the deficient state.

Despite the close link of vitamin D with human health, vitamin D inadequacy is not widely recognized as a problem by physicians and patients. Greater awareness of the problem of a high prevalence of vitamin D inadequacy is required among researchers, clinicians, and patients. Women in the underprivileged sections, both in urban and rural India, are battling inadequate resources, multiparity, imposed customs of clothing, and social vulnerability of the fairer sex which coupled with the urban environmental decay will continue to pose the threat of Vit D deficiency. Special efforts on the medical and social fronts are necessary to combat this preventable epidemic of vitamin D deficiency.

\section{References}

1. Adams JS, Chen H, Chun R, et al. Substrate and enzyme trafficking as a means of regulating 1,25-dihydroxyvitamin D synthesis and action: the human innate immune response. J Bone Miner Res. 2007;22:V20-4.

2. Novakovic B, Sibson M, Ng HK, et al. Placenta-specific methylation of the vitamin D 24-hydroxylase gene: implications for 
feedback autoregulation of active vitamin $D$ levels at the fetomaternal interface. J Biol Chem. 2009;284(22):14838-48.

3. Novakovic B, Sibson M, Ng HK, et al. An experimental investigation on rickets. Lancet. 1919;194:407-12.

4. Viljakainen HT, Saarnio E, Hytinantti T, et al. Maternal vitamin D status determines bone variables in the newborn. J Clin Endocrinol Metab. 2010;95:1749-57.

5. Mahon P, Harvey N, Crozier S, et al. Low maternal vitamin D status and fetal bone development: Cohort study. J Bone Miner Res. 2009;25:14-9.

6. Pasco JA, Wark JD, Carlin JB, et al. Maternal vitamin D in pregnancy may influence not only offspring bone mass but other aspects of musculoskeletal health and adiposity. Med Hypotheses. 2008;71:266-9.

7. Walker V, Zhang X, Rastegar I, et al. Cord blood vitamin D status impacts innate immune responses. J Clin Endocrinol Metab. 2010;96:1835-43.

8. Standing Committee on the Scientific Evaluation of Dietary Reference Intakes. Dietary reference intakes for vitamin D and calcium. Washington, DC: National Academy Press; 2010.

9. Johnson DD, Wagner CL, Hulsey TC, et al. Vitamin D deficiency and insufficiency is common during pregnancy. Am J Perinatol. 2011;28:7-12.

10. Hollis B, Johnson D, Hulsey T, et al. Vitamin D supplementation during pregnancy: Double-blind, randomized clinical trial of safety and effectiveness. J Bone Miner Res. 2011;26:2341-57.

11. National Institute for Health and Clinical Excellence (2008) Antenatal Care Routine care for the Healthy Pregnant Women. NICE Clinical Guideline 62, London.

12. Southern Health (2009) Vit D and calcium in pregnancy and breast feeding information sheet for women (to be developed) clinical protocols and guidelines, Maternity.

13. Bischoff-Ferrari HA, Willett WC, Wong JB, et al. Fracture prevention with vitamin D supplementation: a meta-analysis of randomized controlled trials. JAMA. 2005;293:2257-64.

14. Chapuy MC, Arlot ME, Duboeuf F, et al. Vitamin D3 and calcium to prevent hip fractures in the elderly women. $\mathrm{N}$ Engl $\mathrm{J}$ Med. 1992;327:1637-42.
15. Chapuy MC, Arlot ME, Delmas PD, et al. Effect of calcium and cholecalciferol treatment for 3 years on hip fractures in elderly women. BMJ. 1994;308:1081-2.

16. Lips P, Graafmans WC, Ooms ME, et al. Vitamin D supplementation and fracture incidence in elderly persons: a randomized, placebo-controlled clinical trial. Ann Intern Med. 1996;124: 400-6.

17. Broe KE, Chen TC, Weinberg J, et al. A higher dose of vitamin D reduces the risk of falls in nursing home residents: a randomized, multiple-dose study. J Am Geriatr Soc. 2007;55:234-9.

18. Kunes J, Tremblay J, Bellavance F, et al. Influence of environmental temperature on the blood pressure of hypertensive patients in Montreal. Am J Hypertens. 1991;4:422-6.

19. Woodhouse PR, Khaw KT, Plummer M. Seasonal variation of blood pressure and its relationship to ambient temperature in an elderly population. J Hypertens. 1993;11:1267-74.

20. Krause R, Buhring M, Hopfenmuller W, et al. Ultraviolet B and blood pressure. Lancet. 1998;352:709-10.

21. Pfeifer M, Begerow B, Minne HW, et al. Effects of a short-term vitamin $\mathrm{D}(3)$ and calcium supplementation on blood pressure and parathyroid hormone levels in elderly women. J Clin Endocrinol Metab. 2001;86:1633-7.

22. Peller S, Stephenson CS. Skin irritation and cancer in the United States Navy. Am J Med Sci. 1937;194:326-33.

23. Lappe JM, Travers-Gustafason D, Davies KM, et al. Vitamin D and calcium supplementation reduces cancer risk: results of a randomized trial. Am J Clin Nutr. 2007;85:1586-91.

24. Dembrow M. High vitamin D: Rx for cancer prevention? Clin Advisor. 2007;10:54-7.

25. Pittas AG, Dawson-Hughes B, Li T, et al. Vitamin D and calcium intake in relation to type 2 diabetes in women. Diabetes Care. 2006;29:650-6.

26. Hypponen E, Laara E, Reunanen A, et al. Intake of vitamin D and risk of type 1 diabetes: a birthcohort study. Lancet. 2001;358: $1500-3$. 